La publicación del Informe de la Comisión Interministerial para la modernización del lenguaje jurídico fue, definitivamente, un gran paso hacia esta meta. Sin embargo, parece que tres años después de la aparición del informe (y dos años desde la publicación este libro), el calado de las propuestas de mejora todavía no se ha generalizado.

Sin duda, una de las causas puede deberse a que el discurso jurídico tiene un carácter marcadamente conservador, lo que hace que sea poco permeable a las propuestas de cambio. De ahí que sea necesario insistir, ya sea en nuestra faceta de especialistas en Lenguaje o Derecho, ya sea como ciudadanos particulares, en la optimización de un discurso que no fomenta la claridad.

\title{
Referencias bibliográficas:
}

Cassany, D. (2005): «Plain Language in Spain», Clarity, 53, págs. 41-44.

Gibbons, J. (2003): Forensic Linguistics: An Introduction to Language in the Justice System. Estados Unidos, Blackwell.

VV. AA. (2011): Informe de Recomendaciones de la Comisión para la Modernización del Lenguaje Jurídico. España: Ministerio de Justicia. (04-03-2014) https://www. administraciondejusticia.gob.es/paj/publico/ciudadano/informacion_institucional/mode rnizacion/modernizacion_lenguaje_juridico/!ut/p/c4/04_SB8K8xLLM9MSSzPy8xBz9CP 0os3gzT1dTz6BgExNjA0szA08vgwBjc0NnAwt_Q_2CbEdFADG1jrE!/

CRISTINA VilLaLBA IBÁÑEZ

Universitat de València

Muñoz-Basols, J., Gironzetti, E. y Pérez, Y.: ¡A debate! Estrategias para la interacción oral, Madrid, EDELSA Grupo Didascalia S.A., 2013.

Este manual de ELE contribuye a la mejora en la calidad de los materiales destinados a impartir una L2, ya que aporta un valioso catálogo de actividades, precisamente, para el nivel avanzado, teniendo en cuenta que la mayoría de recursos disponibles están diseñados para los niveles iniciales o intermedios.

Desde el título, los autores manifiestan sus principales objetivos: la orientación comunicativa y el propósito de dedicarse a las destrezas orales e interactivas. En efecto, el debate constituye un género oral próximo a la conversación cotidiana, pero con la figura de un moderador (en este caso, el docente), para que los aprendices de ELE interactúen con mayor o menor grado de planificación: desde intervenciones muy elaboradas - con antelación, en casa-, medianamente preparadas —en el acto, en clase-, hasta improvisadas, más espontáneas, ejemplos cercanos a la oralidad nativa. Además, como género textual en auge, el debate sirve de banco de pruebas pragmático (pone en juego la lengua en uso) y favorece el aprendizaje de diversos componentes de la competencia pragmática (definidos en el Plan Curricular del Instituto Cervantes). 
El material completo reúne tres elementos complementarios: el manual del alumno, ¡A debate!, que incluye un CD de audio y la Guía metodológica, para el profesor. El primero consta de diez unidades temáticas o didácticas con actividades comunicativas para C1 y C2. En el Prólogo, y también en la contraportada, los propios autores destacan el carácter idóneo de esta publicación puesto que se basa en entrevistas de personajes conocidos sobre temas de actualidad; estructuras comunicativas y funciones lingüísticas; diversos géneros orales (exposición, debate, tertulia, conversación, conferencia); así como en un marco intercultural (puesto que amplía cada unidad a su vertiente internacional con información relacionada correspondiente a los países de habla hispana); y contiene un dosier gramatical práctico (para afianzar la competencia gramatical del alumno).

También subrayan que las actividades propuestas tratan de potenciar tres macrofunciones del nivel avanzado: la conversación, la exposición y la argumentación; sin dejar de lado la narración, así como la comunicación no verbal, tan presentes en la comunicación cotidiana. En efecto, si se echa un vistazo al índice de contenidos, se observa que el manual resulta muy completo e intenta ofrecer un marco amplio de posibilidades en el que desarrollar plenamente la interacción oral del alumnado.

Cada unidad consta de seis bloques o apartados de contenido:

- el tema, punto de partida de la unidad, que es siempre de actualidad y de interés para un aprendiz de español adulto: sociedad, cine, comunicación, música, ciencia, trabajo, literatura, salud, economía o humor.

- los contenidos lingüísticos, que se componen, en su mayoría, de una amplia selección de léxico del ámbito o tema de la unidad, así como de unidades léxicas más complejas como las pluriverbales (colocaciones, locuciones, u otras unidades fraseológicas - UF-, en general).

- los contenidos culturales, o conjunto de informaciones, noticias y contenido enciclopédico (que corresponderían a la parte de pragmática intercultural) sobre los temas elegidos, con opiniones, para que sirvan de modelo al alumnado en el debate final.

- la producción textual, en la que se desarrollan diversas tipologías especialmente, la expositiva- y géneros textuales, no solo informativos o de tipo expositivo y descriptivo (como la noticia, la sinopsis cinematográfica, el informe, la descripción enciclopédica o la biografía); sino también de creación estilística (como la narración, la elaboración de un poema, o el diseño de un eslogan publicitario humorístico).

- la expresión e interacción orales: este es el aspecto más destacable de cada unidad, ya que constituye el principal objetivo del manual. Se basa en el desarrollo de un debate, de ahí el título, para el que proporcionan una serie de recursos comunicativos y estrategias, relacionados con determinadas funciones comunicativas que el aprendiente de E/LE debe alcanzar de manera competente: valorar y pedir opiniones; argumentar y contraargumentar; aconsejar; destacar un elemento; expresar (des)acuerdo; expresar sorpresa, interés, (des)conocimiento, (falta de) certeza, hipótesis, indiferencia o escepticismo, entre otros. Entre las estrategias presentadas, ofrecen también 
como recurso algunos conectores, o el modo de participar o actuar en determinados géneros orales, tanto en el debate, como en la tertulia o en la conversación telefónica, o bien si han de recitar o contar un chiste. En algunas unidades, antes del debate, se ofrece al alumno un modelo de discurso (tertulia, conferencia, gráficos, conversación telefónica...) que sirva para el comentario previo y como punto de arranque para el debate propuesto en cada caso.

- $\quad y$, por último, el manual se completa con el dosier gramatical, en el que, tras un rápido índice, tema a tema se repasan los aspectos gramaticales más útiles para el alumnado: usos del indicativo y del subjuntivo completando oraciones con la forma del verbo adecuada; oraciones con valor concesivo o adversativo, para expresar contraste u oposición; uso de conectores; formas verbales de pasado; perífrasis verbales; uso del artículo (determinado e indeterminado); transformación de oraciones en voz pasiva; usos de ser y estar y los adjetivos que se emplean con cada uno; posición del adjetivo (antepuesto o pospuesto); formas no personales del verbo; estructuras condicionales, temporales, causales, finales, consecutivas y comparativas; uso de preposiciones y verbos con preposición; oraciones de relativo; uso de pronombres (se, objeto directo e indirecto) y el estilo directo e indirecto.

Por tanto, este apéndice supone el apoyo necesario al que el aprendiz puede acudir para preparar sus tareas e intervenciones, como consolidación de su competencia gramatical y como resumen de los contenidos que debe ser capaz de utilizar en este nivel.

En cuanto al diseño particular de cada tema, la organización de los contenidos es homogénea y se estructura en varias secciones que le confieren la uniformidad necesaria en esta clase de obras didácticas. Cada tema se presenta a doble página y se inicia con diversas actividades de preguntas directas, afirmaciones de otros y ejercicios de selección múltiple para comprobar el significado de ciertas unidades fraseológicas (por ejemplo, 'tener el mundo en tus manos', 'curarse en salud' o 'tanto tienes, tanto vales').

La segunda sección, bajo el epígrafe En portada, contiene normalmente una entrevista (escrita o transcrita, normalmente adaptada) sobre la que se plantean actividades de comprensión lectora (verdadero/falso, preguntas directas). A continuación, se amplían los contenidos de la unidad con Más palabras, bloque que profundiza en el conocimiento del sistema, especialmente del léxico, tanto sustantivos o adjetivos, como unidades fraseológicas y otras unidades pluriverbales de significado más técnico, como las locuciones ('de maravilla', 'sin trampa ni cartón'), las colocaciones ('promulgar una ley', 'convocar una huelga'), expresiones idiomáticas ('ser coser y cantar', 'ser un manirroto'), refranes ('al que madruga...') o verbos relacionados, con indicación de sinónimos y antónimos, para aumentar el vocabulario que luego se ha de utilizar en el debate. También se repasan las voces o prefijos cultos, así como las definiciones o distinción entre las acepciones de ciertas unidades polisémicas.

En el bloque que titulan Destacado aportan textos o imágenes sobre asuntos de actualidad que el alumnado puede conocer y sobre los que se pide su opinión; para ello, se le ofrecen recursos comunicativos con los que valorar y pedir valoración, expresar 
acuerdo o desacuerdo, realizar un esquema o resumen, según las funciones lingüísticas que se trabajen en ese tema.

La unidad se completa con el apartado Especial Mundo Hispano, en que se amplía el tema tratado con su dimensión internacional, concretamente, de los países de habla hispana. Suelen aportarse pequeñas informaciones sobre personajes relevantes en la materia tratada (salud, economía, humor...) y actividades de diverso tipo: de relación, búsqueda de información, respuesta libre con la opinión del alumno, por citar algunas.

Por último, el Cierre concluye la unidad con el apartado sobre interacción y se trabaja el debate propiamente dicho, con diversos recursos comunicativos y estrategias más específicas.

Para concluir este apartado descriptivo sobre el manual, queremos destacar la gran variedad de tipología de actividades que se descubren a lo largo de los temas tratados: preguntas directas; actividades de selección múltiple (de 2-3 respuestas); comentario de afirmaciones, textos, imágenes o conocimientos previos; verdadero/falso; elaboración oral de una biografía a partir de una lista de datos; lectura (comprensión escrita); relacionar listas o imágenes con textos; completar tablas; producir ejemplos de uso a partir de un modelo; rellenar huecos; ordenar enunciados por importancia; redacción (expresión escrita); explicar el significado del vocabulario y expresiones idiomáticas; escuchar (comprensión auditiva); preparar una presentación oral; generar palabras o estructuras a partir de un ejemplo: rápido > rápidamente; interpretar una gráfica; recitar o leer con la entonación adecuada un escrito; completar la segunda parte de un enunciado bimembre (refrán, frase hecha); identificar un elemento gramatical, léxico, retórico... en un enunciado; practicar la expresión e interacción orales: leer, recitar, argumentar, contar un chiste, realizar una conferencia o exposición... Esta es, sin duda, una de las grandes cualidades del manual, pensado, además, para favorecer los diversos agrupamientos del alumnado según las actividades: individuales, en parejas, en pequeños grupos o toda la clase.

El segundo de los materiales que contiene esta edición es el CD de audio (para el alumnado), en el que se incluyen 12 grabaciones para realizar las tareas correspondientes (como las entrevistas, bien para responder cuestiones, bien para comprobar un ejercicio), de manera que el alumno puede consolidar la destreza de la comprensión auditiva. Este material, al incluirse en el manual del alumno, le confiere autonomía total para resolver y comprobar el grado de comprensión de un discurso y le permite practicar la entonación, la pronunciación de determinados sonidos, e incluso el tono de ciertas respuestas (sorpresa, alegría...). Su calidad sonora es excelente y las voces seleccionadas vocalizan e interactúan con notable naturalidad, no son espontáneas, pero garantizan la preparación necesaria para un material didáctico.

El tercer componente de la edición es la Guía metodológica (para el profesor), sin duda, el de mayor utilidad para el docente, que a buen seguro recurrirá a él en el día a día para preparar sus sesiones de clase. Como informan los autores al principio de la guía, además de instrucciones didácticas, solucionario y transcripción de algunas pistas de audio del $\mathrm{CD}$, se ofrecen comentarios sobre cómo integrar la gramática en cada tema e, incluso, en algunos casos, actividades de ampliación (fotocopiables, como tarea final). 
Por último, se incluyen fichas para mejorar la expresión oral mediante las nuevas tecnologías, individualmente o en equipo.

La parte más significativa de la guía es, sin duda, el conjunto de recomendaciones metodológicas: se proporcionan pautas para la planificación de las tareas, su temporalización, la distribución del aula (grupos, parejas...), se proponen posibles interpretaciones para orientar al alumnado cuando se le pide su opinión personal, se sugiere el papel del docente en cada tarea (observador, guía-orientador, participante activo...), según explique, lea, pregunte al alumnado, modere sus interacciones en los debates y en las actividades previas, corrija los ejercicios en voz alta y comente las respuestas, compruebe que se ha comprendido un contenido, especialmente, el idiomático, amplíe las actividades o el léxico que se trabaja, seleccione un material audiovisual para comentar en el aula, supervise las dinámicas planteadas o motive su participación, por citar algunas de sus funciones pedagógicas.

Tras esta parte más descriptiva, nos centraremos en diversos aspectos didácticos que atañen a una programación de idiomas para comprobar en qué medida este manual supera a otros de su nivel.

En primer lugar, en cuanto a los contenidos, los autores tratan los propios del nivel avanzado y desarrollan el aprendizaje y uso de diversas tipologías textuales, especialmente, aquellos ligados a la oralidad, poco trabajados en otros manuales de este nivel (o incluidos solo en materiales de 'Español negocios' pero no con temas de interés general, como en este caso, dirigido a un tipo de aprendiz mucho más amplio, no solo del ámbito empresarial). Este es, por tanto, uno de los méritos de esta edición, apta para cualquier clase de ELE del nivel avanzado. Si bien, consideramos que, en la presentación del tema (En portada), podrían haberse elegido otros géneros, no solo la entrevista, aunque bien es cierto que es un género dialógico, centrado en la interacción y eminentemente oral (incluso las variantes escritas, como las electrónicas, siempre requieren de la simultaneidad de entrevistador y entrevistado, es decir, es un género interactivo que pone en juego estrategias de elaboración, retroalimentación o reformulación no presentes en otros géneros y fundamentales en el uso efectivo de la lengua).

Asimismo, citan numerosas entrevistas y artículos de prensa, películas, páginas electrónicas y blogs, discos, novelas, poemas y poemarios, canciones y videoclips, citas de personajes famosos, eventos. Dicho de otra manera, ofrecen un abanico muy amplio de discursos concepcionalmente orales, aunque transcritos en el manual. Quizá hubiera sido interesante recomendar al alumno alguna página electrónica de acceso gratuito a contenidos audiovisuales de los géneros textuales que se trabajan, como alguna entrevista, conferencia o, especialmente, debates, para proporcionar modelos de interacción reales, así como atender a otros factores comunicativos de tipo pragmático como los recursos paralingüísticos (postura, gestualidad, proxémica, kinésica...) con que muchas veces se acompañan, refuerzan e, incluso, se expresan los argumentos y opiniones. O bien, incluir alguno de estos discursos orales en el CD, para evitar la volatilidad de los contenidos en la red y garantizar el acceso adecuado a ese material real, sin publicidad u otros inconvenientes que pudieran interferir en la visualización de ese contenido. 
De esta excelente variedad de discursos, los textos extractados de la prensa, en concreto, son también reales, aunque adaptados, para conservar la coherencia didáctica necesaria en un manual de ELE. Respecto a su procedencia, aunque a veces se indica que provienen de «varias fuentes», sin especificar o concretar más, en la mayoría de los casos se cita en el manual del alumno la fuente completa de donde procede el texto: páginas electrónicas de diversos medios de comunicación o especializadas, o del personaje o asunto del que se está tratando. Asimismo, se menciona en los agradecimientos a la periodista que ha efectuado algunas entrevistas pero no se indica en qué medio aparecieron originariamente. También en el dosier se incluye un texto procedente de un medio electrónico de contenidos audiovisuales gratuitos pero no se especifica si es la transcripción de una tertulia, mesa redonda, debate $u$ otro tipo de discurso; quizá porque no resulta relevante para esa actividad en particular. Por otra parte, las pistas del CD son entrevistas adaptadas, grabadas por locutores y no con sus participantes reales (entrevistadora y entrevistado), por lo que se pierde cierta naturalidad y el resultado se aleja de la lengua nativa, deseable para un C2; a cambio, se consiguen grabaciones con una perfecta dicción, entonación y cadencia, más adecuadas para el propósito didáctico de la obra. No se cita a los locutores, quizá de la propia editorial, pero sí, como venimos destacando, las fuentes de la mayoría de los textos, poco habitual en otros manuales, pero recomendable $y$, por tanto, es un valor añadido más de este material.

Desde el punto de vista de la metodología, desde el inicio se postula el debate como género idóneo para desarrollar plenamente la oralidad, así como para complementar todas las destrezas orales (escuchar, hablar y conversar o interactuar, detalladas en el $M C E R)$. Esta decisión metodológica concuerda, de nuevo, con el enfoque comunicativo, centrado en la consolidación de las funciones comunicativas y la resolución de pequeñas tareas.

Otro de los aspectos esenciales en didáctica de segundas lenguas es el papel que docente y aprendiz asumen durante el proceso de enseñanza-aprendizaje. En este caso, dada la homogeneidad en la presentación de los contenidos y en el diseño de la tarea final de cada unidad - el debate-, el alumnado puede asumir la iniciativa en la organización de las sesiones de aula, pues ya sabe qué ha de lograr al final de cada tema y cómo ha de conseguirlo. Asimismo, desde el principio se potencian las actividades donde el aprendiz es el protagonista: son sus opiniones las que interesan, sus argumentos, la postura ante los temas presentados, y lo primordial es su participación, que interactúe con sus pares, no solo que conozca en qué consisten un debate, una tertulia o una presentación, sino que sea un interlocutor activo y eficaz en cada uno de los géneros en que se vea involucrado.

En este contexto, el papel del docente es, sobre todo, el de guía, acompañante del proceso, para sugerir pautas y resolver dudas concretas, así como de moderador en los debates y demás tareas de confrontación de opiniones. De esta manera, las prácticas orales ganan efectividad, pues simulan interacciones reales donde lo importante es compartir y comunicarse. Relacionado con la labor del profesor, para finalizar el repaso de los aspectos didácticos que se tienen en cuenta en el diseño de esta edición, observamos que la evaluación es continua, ya que en todas las unidades se practica a 
conciencia la oralidad, y el docente ha de llevar a cabo una supervisión constante de la consecución de los objetivos y de los progresos en las competencias del alumno, a partir de las estrategias propuestas. Para ello, cuenta con la ayuda inmejorable de la guía didáctica, en la que, además, encuentra material fotocopiable que sirve como conjunto de pautas (no solo para el alumno) y seguimiento de la tarea final, que el docente puede reconvertir en rúbrica o como guía de evaluación, pues de ahí puede extraer qué aspectos han de ser evaluados para realizar correctamente cada actividad. En estas tareas también se procura que empleen las nuevas tecnologías como herramienta en el aprendizaje de la lengua y la cultura.

También el dosier gramatical sirve de repaso y (auto)evaluación para el alumno, que puede utilizar su material con total autonomía; por tanto, se fomenta el autoaprendizaje, tanto en la búsqueda de información como en la resolución y comprobación de las tareas, mediante las actividades propuestas y mediante el CD de audio con las grabaciones de las entrevistas.

Revisado el manual, queda patente la extensa experiencia docente de los autores, que se anticipan a posibles dificultades del proceso de enseñanza-aprendizaje y van más allá en esta propuesta didáctica, ya que persiguen el uso efectivo de la lengua en uso, ofrecen temas sugerentes y motivadores para un alumnado adulto al tratarse de textos de actualidad, sobre los que sin duda tendrán formada una opinión y podrán interactuar sin problemas.

El diseño del material y su organización responden perfectamente al propósito de desarrollar las destrezas orales en un alumno de nivel avanzado, siempre exigente en este aspecto del aprendizaje del idioma. Gracias a su variedad temática y a su riqueza en actividades y estrategias, se adaptan a cualquier grupo de alumnos, por lo que cualquier escuela, academia o centro de idiomas, o universidad debería contar con un material como este para sus clases de conversación o, incluso, como manual del nivel avanzado a partir del cual integrar los contenidos gramaticales, tal y como proponen en la Guía metodológica; pero también es recomendable para alumnos que quieran mejorar por su cuenta las destrezas orales, con la ayuda del CD y del resto de elementos de autoaprendizaje, si bien practicando con otros interlocutores, aprendices o nativos, con quienes poner en uso las estrategias recomendadas por los autores.

Por otro lado, esta edición también puede recomendarse como modelo a todos aquellos docentes o creadores de materiales (no solo de ELE, también de español como L1) que deseen elaborar una obra a partir de su experiencia de aula, ya que aportan una valiosa muestra de tipos de actividades y un diseño totalmente coherente para el propósito didáctico que se persigue.

En síntesis, ;A debate! resulta un material perfecto para practicar, afianzar y lograr la competencia necesaria de las destrezas orales en el nivel avanzado y, sin duda, la edición es muy recomendable para cualquier aprendiz de este nivel. 